\title{
Measuring the Cost Impact of Hospital Information Systems: 1987-1994
}

\author{
Ron Borzekowski * \\ Board of Governors of the Federal Reserve System
}

September 10, 2002

\begin{abstract}
This study measures the impact of information technology (IT) use on hospital operating costs during the late 1980's and early 1990's. Using a proprietary eight-year panel dataset (1987-1994) that catalogues application-level automation for the complete census of the 3,000 U.S. hospitals with more than 100 beds, this study finds that both financial/administrative and clinical IT systems at the most thoroughly automated hospitals are associated with declining costs three and five years after adoption. At the application level, declining costs are associated with the adoption of some of the newest technologies, including systems designed for cost management, the administration of managed care contracts, and for both financial and clinical decision support. The association of cost declines with lagged IT as well as the cost patterns at the less automated hospitals both provide evidence of learning effects.
\end{abstract}

\footnotetext{
${ }^{*}$ Board of Governors of the Federal Reserve System, Washington, DC 20551. e-mail: ron.borzekowski@frb.gov. The views expressed in this paper are those of the author and do not necessarily reflect those of the Board of Governors or the staff of the Federal Reserve System. I am grateful to Frank Wolak, Mark McClellan, Tim Bresnahan, Doug Bernheim, and Will White for their comments and suggestions. Many thanks as well to the seminar participants at Stanford and at the 2002 AEA meetings for their input. Funding for the data for this work was graciously provided by the National Bureau of Economic Research and the Stanford Computer Industry Project. In particular, special thanks to Shirley Tessler, Jeffrey Geppert, and Ronda Burginger for their assistance.
} 


\section{Introduction}

Hospitals are highly information intensive organizations which spend substantial sums on information management and processing. It naturally follows that technologies that improve the gathering, storage, transmission, and processing of information would be useful tools in hospital management. In fact, as early as the 1960's, hospital administrators in the U.S. began to adopt a variety of information technologies (IT) with the goal of improving quality, reducing costs, and improving operations (Harrington 1964). ${ }^{1}$

The goal of this work is to measure the impact of information technology use on hospital operating costs during the late 1980's and early 1990's. ${ }^{2}$ Using a new and broad dataset of hospital IT that contains application-based (software based) measures of IT use, this study assesses whether the adoption of HIS is associated with reductions in operating costs in subsequent years. In addition, detailed application-level data is used to isolate specific systems associated with reduced costs as well as the mechanisms that underlie these changes.

The basis for this study is a proprietary eight-year panel dataset (1987-1994) that catalogues the degree of automation at the application level for the complete census of nearly 3,000 U.S. hospitals with more than 100 beds. These data provide a solution to a substantial problem in IT measurement as they are the first that measure the number and type of applications that are automated, regardless of their location within or outside the firm. Outsourcing of hospital IT is common during this period and as a result, application-based measures of IT are more appropriate for this industry. ${ }^{3}$

To measure IT's effects, this study estimates a series of fixed-effects panel regressions, utilizing data from the American Hospital Association, the Medicare Cost Reports, and the IT dataset. Variable costs are regressed separately on three measures of IT, all based on the application-level

\footnotetext{
${ }^{1}$ The January 1964 issue of Hospitals: Journal of the American Hospital Association was a special issue on "Automatic Data Processing in Hospitals." At the time, thirty-nine hospitals in the U.S. were using computers. See Collen (1995) for a comprehensive history of hospital information systems.

${ }^{2}$ In this sense, this study follows the long series of work on issues of productivity and IT. Since most of the earliest studies found little or no increased productivity, the result is what was labeled the "productivity paradox." See Brynjolfsson (1993), Brynjolfsson and Yang (1996), and Devaraj and Kohli (2000) for reviews of this literature.

${ }^{3}$ The recent rise of server-resident applications and the outsourcing of much of e-commerce IT will elevate this IT measurement issue for future researchers studying other industries.
} 
data, and each utilizing lagged values of the IT variables. The first measure captures the overall IT intensity of the firm in both the financial/administrative area as well as the clinical domain. The second and third measures capture any cost effects from individual applications and from groups of applications, respectively. Taken as a set, these three measures offer not only evidence on whether reduced costs are found at more automated hospitals, but also clues regarding the mechanisms by which cost changes occur.

The current results find significant associations between hospital information systems and hospital costs. In particular, the aggregate results indicate that adoption of new systems at the most thoroughly automated hospitals is associated with lower operating costs three and five years after adoption. In contrast, the least IT intensive hospitals show higher costs after adopting new systems. Further, this pattern is evident within both the financial/administrative domain as well as the clinical domain.

These results are mirrored in the application-level regressions. Adoption of older systems within either domain is associated with rising costs after adoption while adoption of newer financial management and patient care systems is associated with lower costs. The unifying feature of many of these latter systems is their ability to provide newer and better information to decision makers, regardless of the domain in which they lie. As well, the clinical systems may aid managers in monitoring doctors' behavior. Cost savings seem to arise from increasing the productivity of decision makers or from solving the hospital's agency problems. In contrast, there is little evidence that systems which simply automate information processing have the same effect.

There are two reasonable explanations for the rising costs associated with adoption at the less automated hospitals: unobserved time-varying hospital effects that drive both higher costs and slower adoption, and learning effects. To rule out the first explanation, state-level trends are included in the regressions. As well, additional regressions are performed which cast doubt on the importance of these unobserved effects. Instead, the more likely explanation is based on learning effects: the organizational costs of HIS adoption are higher at less automated hospitals (as a result of their inexperience) resulting in higher operating expenses. The importance of learning effects is also supported by the evidence showing lags in costs reductions until three or five years after 
adoption.

The next section focuses on hospital costs, laying out the background and motivation for the empirical approach of this study. It outlines the potential savings from the use of information technologies, describes how IT may impact the use of both fixed and variable resources, and details the precise mechanisms by which this may occur. Section 3 builds on this discussion, developing a more formal model of hospital behavior and deriving the regression equations. The various application-based measures of IT are also detailed. The results of the estimation are described in Section 4 while the final section offers a discussion of the results and future directions for research.

\section{Hospital Costs and the Role of IT}

This section focuses on hospital costs, laying out the background and motivation for the empirical strategy of this study. Potential savings from the use of information technologies are outlined and IT's potential impact on the use of both fixed and variable resources is discussed. The precise mechanisms by which this may occur are also discussed in order to motivate the empirical specification as well as the interpretations of the results.

The Harris (1977) model of the hospital serves as the underlying framework for this analysis. This model highlights the structural features of the hospital and allows a precise delineation of

hospital costs. In turn, the model offers the opportunity to identify information related problems exacerbating costs as well as the possible savings that IT may engender. An analysis of these costs and the associated savings from IT are the focus of this section.

According to Harris (1977), a hospital can be viewed as "one organization split into two disjoint pieces, each with its own objectives, managers, pricing strategies and constraints" where "the medical staff and the administration are locked in a non-cooperative oligopoly type game." Harris goes on to explain that the firm is made up of an array of specialized suppliers and demanders. On the supply side, certain functionally-oriented departments, such as the pharmacy, operating rooms, and blood bank stand ready to assemble and deliver a particular input. On the demand side, various doctors decide which patients need which ancillary services and when. 
In Harris' model, the hospital costs are clearly located. The majority of costs derive from the labor, capital, and material used in each of the departments that Harris labels 'specialized suppliers'. The treatment of each patient requires some mix of these inputs and the hospital bears the cost of providing them. These costs are labeled as 'primary input costs' and two particular features of hospitals make IT an effective way to control them.

First, as Arrow (1963) notes, the provision of health care is characterized by inherent uncertainty: accurate diagnoses are hard to come by, the selection of one of many possible interventions creates difficult decision opportunities and even the efficacy of treatments for a given patient are uncertain. As such, any information technologies that aid in diagnosis or that offer decision support regarding treatment plans would help lower cost. Using IT systems, medical personnel can get more or different information regarding patients and treatments so that they might dispense better care. A system can suggest the most appropriate antibiotic for a new illness or more accurately track certain vital signs allowing easier detection of a worsening condition. Furthermore, a system could alert doctors to drug-drug interactions or other adverse events relating to a given prescription. In any of these cases, the HIS can be seen as reducing the uncertainty regarding a given treatment or condition, better informing the medical care provider.

To understand the second way that primary input costs can be reduced, note that health care is an environment where incentives may not align and where complex process abound between doctors, patients, administrators and third-party payers. In particular, physicians control approximately $70 \%$ to $80 \%$ of all health care dollars spent (Pestotnik et al. 1996) while hospitals bear the cost of these decisions. A problem arises since the objectives of doctors and hospitals are often at odds; while the hospital is willing to provide care up to the point where marginal benefits may equal marginal costs, doctors face other incentives and may wish to provide more care. ${ }^{4}$ Such incentives could be the well-being of the patient who wants care until marginal benefits are zero, incentives of defensive medicine which can push the limit even further (McClellan and Kessler 1996), or financial incentives (Gruber and Owings 1996). In all these cases, a classic moral hazard situation exists and the hospital may invest in IT to serve as monitoring technology.

\footnotetext{
${ }^{4}$ Physician incentives are reviewed by McGuire (2000) in the recent Handbook of Health Economics.
} 
Hospital information systems can monitor medical practitioners in two ways. First, the system could prohibit the doctor from performing certain tests or ordering certain drugs. If all orders must go through the automated system, then the doctor might be forced to go to greater lengths to obtain services for the patient, even making side deals with ancillary departments or transferring the patient. In essence, these orders would effectively be stopped. More likely, the implementation of an IT system could allow the hospital to record and analyze the doctor's actions. In one example, a hospital was able to determine that a surgeon was taking twice as long to perform his surgeries as any other doctor. Other systems may track a given doctor's use of medications, advanced diagnostic technologies, or radiological services. The sheer act of recording these events or feedback given to the doctor may deter these activities.

A second type of hospital costs are those incurred to run the organization. These are further divided into two sets: those costs that reside entirely in the administrative section of the hospital, and those that help coordinate activity across different parts of the hospital. The first of these are administrative costs. These are common to all modern organizations and include costs such as completing payroll and purchasing supplies. The second are coordination costs. As Harris describes, the hospital is comprised of a multitude of specialized departments and suppliers. Laboratory services are located in one unit while radiological testing and diagnoses are performed elsewhere. Other departments include the ICU, blood bank, dietary services, linen support, operating rooms and others. Such hospital organization requires that a tremendous amount of information flow from one unit to the other, and between these units and the administrative realm. Clinical data resides on the patient's chart while more administrative data is maintained in other filing systems. With this level of decentralization, coordination costs are likely to be quite high.

In fact, a recent study concluded that administrative costs at U.S hospitals in 1994 averaged $26 \%$ and averaged over $30 \%$ at for-profit hospitals (Woolhander and Himmelstein 1997). A much earlier study, specifically focused on the costs of information handling in hospitals, found these costs to range from $22 \%$ to $25 \%$ of total hospital costs (Jydstrup and Gross 1966). Clearly, any hospital IT can simply automate the flow of information within the hospital, potentially reducing costs. As an example, consider installing a computer system near the patient's bed, linking the 
system to another in the pharmacy, and automating transmission of medication orders. This alone may reduce costs as less paper is generated, fewer mistakes are made, and information is transferred faster.

This brief discussion highlights several attributes of hospital IT as well as IT's role in managing costs. It highlights the distinction between potential short run savings in variable costs and longer run savings in fixed costs that motivates the short run specification of the cost function. As well, it develops a correspondence between certain HIS and the costs that they can impact. This correspondence not only motivates the analysis based upon individual applications, but also allows richer interpretation of the results. Each of these institutional features is discussed below before the specification of the empirical model.

In all of the cases described above, the degree to which costs are fixed limits or even prohibits any short-run cost reductions from IT. By definition, fixed costs cannot be altered in the short-run and therefore any IT impact on such resources will not manifest in cost changes. ${ }^{5}$

To be more specific, consider systems that automate particular transactions. Cost savings are easy to recognize as less labor or materials are needed to process data and only necessary learning within the organization delays these cost savings. In contrast, a monitoring technology that limits the use of a particular fixed asset will only show savings in the very long run. No short-term savings will be realized (except from complementary labor or materials) since the reduction in the use of the asset has no impact on cost. Only after its removal (assuming demand falls far enough) would costs fall. In this case, cost changes from IT will occur only after a considerable delay.

The discussion above offers an outline of various costs and then indicates how HIS can reduce them. Reversing this correspondence offers the opportunity to assess the mechanism by which a given system can solve the information problems in the hospital. All systems have the potential to lower some administrative costs, yet only cross-organizational systems can impact coordination costs. Payroll or accounts payable systems automate routine tasks, substitute technology for labor and can help with administrative costs. In contrast, patient care systems that link departments, or

\footnotetext{
${ }^{5} \mathrm{~A}$ recent study examining the cost structure of a large urban public teaching hospital classified about $84 \%$ of hospital costs as fixed. This included the costs of salaried personnel which totaled $58.5 \%$ of total costs (Roberts et al. 1999). As a result the true percentage of fixed costs most likely lies between $25 \%$ and $84 \%$.
} 
ADT systems that can provide a number of individuals the necessary data about patients' status, are likely to aid coordination. Similarly, only systems that provide new information to doctors can improve medical decision making. Systems that can automatically check for drug-drug or drugpatient interactions have a profound ability to alter medical care. ${ }^{6}$ Most of these however require a rudimentary clinical data repository to be effective. Lastly, only systems that explicitly relate information about doctors' behaviors to management are likely to solve the monitoring problem. Billing systems have had this capacity in the past, yet the expansion of systems into the clinical arena allows faster, more accurate, and more definitive information to monitor providers.

\section{Empirical Model and Data}

The empirical strategy in this paper is to specify and estimate fixed-effect panel regressions using various measures of IT as predictors of hospital variable costs. This approach is used to illuminate any associations between IT and costs. Using different measures of IT allows inference regarding the mechanisms by which IT impacts costs as well as the specific functional areas of the hospital associated with declining costs.

The first step in the analysis is the derivation of a simple model of hospital behavior. In section 3.2 , this model is then used to specify the variables included in the linear regression equations and to guide interpretation of the coefficients. The non-IT data used in this study is then described in the following section while the the last section describes the IT variables. In particular, each of the three measures used in the analysis is motivated and described.

\subsection{Model}

To determine the relationship between IT and hospital costs, the analysis begins with the specification of a behavioral variable cost function for hospitals. The model is then used to specify and interpret the empirical equations.

While most previous research on IT productivity has been done in a production function setting,

\footnotetext{
${ }^{6}$ For examples, see the series of articles describing the systems at LDS hospital (e.g. Pestotnik et al. (1996)) and at Brigham and Women's (e.g. Bates et al. (1994)).
} 
the cost function is used here. The difficulty in quantifying hospital output, as well as its multiproduct nature, makes the cost function a cleaner approach. As well, this strategy allows more direct comparison to much of the earlier work on hospital production. ${ }^{7}$

The choice to use a short-run specification predicting variable costs, conditional on the capital stock, is driven by the nature of the hospital industry, in general, and issues regarding the effects of IT, more specifically. There is little reason to believe any hospital is in long-run equilibrium, especially given the recent turmoil in the industry. In fact, several studies have shown that long-run models will be rejected in favor of short-run cost functions (Carey 1997).

More importantly, variable costs are the most likely location to find the effects of HIS, unless one examines the very long run. As discussed in Section 2, these systems have the ability to reduce costs by either lowering the high administrative costs of hospital management, or by reducing the use of medical inputs. This latter effect arises either by aiding the decision making process of medical practitioners or by reducing the incentives for doctors to overutilize hospital resources for their patients.y

In any of these cases, the reduction in labor and materials will may be visible in the short run: it is only after these reductions reach some critical threshold that fixed costs could be reduced. Consider the reduction in bed use and length of stay from better monitoring of doctors admitting and discharge behavior. Only after the reductions warrant the closing or conversion of a ward will fixed costs be impacted. Until that point, the variable costs of linens and staffing will be the only costs reduced. It is this reasoning that motivates the short-run specification used here.

Under the assumption that hospitals were profit maximizing or at least cost minimizing organizations, the specification of the cost function would be straightforward. Total variable costs would be expressed as a function of prices and outputs and, in effect, one would be estimating the dual of the production function. In the case of hospitals, however, there is little agreement about the underlying objective function. While many have argued that little difference exists in the behavior of for-profit and not-for-profit hospitals, the mere presence of both types of organizations suggests

\footnotetext{
${ }^{7}$ Some of the most recent work on hospital productivity does involve multi-product production functions. As well, both DEA and frontier regression methods have recently been used with cost functions. These alternative methods are open avenues for research in this arena.
} 
motives away from pure profit maximization. ${ }^{8}$

In the current model, hospitals are assumed to value some combination of patients' utility $(H)$, medical education $(E)$, quality of care provided $(\eta)$, and profits $(\Pi) .{ }^{9}$ In the broadest specification, the value that each hospital places on each of these factors can vary. For example, almost by definition, teaching hospitals place a greater value on medical education than other hospitals. Thus, hospitals are assumed to maximize the following value function:

$$
V_{i t}=V_{i}\left(H_{i t}, E_{i t}, \Pi_{i t} ; \eta_{i t}\right)
$$

Placing $H_{i t}$ directly in the value function of the hospital assumes that patients care solely about their final health status after treatment by the hospital. As for quality, the model simply asserts that quality is an exogenous characteristic of the hospital. Quality is included as one argument in the value function and is also allowed to impact costs. ${ }^{10}$

Four constraints also impact a hospital's final choice of inputs.

$$
\begin{gathered}
H_{i t}=H\left(L_{i t}^{h}, M_{i t}, K_{i t}, E_{i t}, Y_{i t}, H_{i t}^{o} ; \omega_{i t}\right) \\
E_{i t}=E\left(L_{i t}^{e}, H_{i t}, H_{i t}^{o}\right) \\
Y_{i t}=Y\left(X_{i t}, \eta_{i t}\right)
\end{gathered}
$$

\footnotetext{
${ }^{8}$ See Ellis (1993) for a careful discussion regarding the specification and interpretation of hospital cost functions.

${ }^{9}$ Medical education is included in the model since prior research has shown hospital costs to be higher at teaching hospitals.

${ }^{10}$ This specification ignores the fact that IT may improve hospital quality. In this period, it is unlikely that this effect would be large except at a small fraction of hospitals.
} 


$$
\Pi_{i t}=\sum_{p \in P P S} R+\sum_{p \in F F S}(1+\theta)(w L+r K+m M)-w L-r K-m M
$$

The production technologies described in the first two constraints govern what outputs can be created from which inputs. The first specifies total health output produced at a given hospital as a function of the labor devoted to health, $L^{h}$, materials $M$, and non-IT capital $K$ used in the production process as well as the number $Y$ and illness level (or initial health) $H^{o}$ of the hospital's patients. Heterogeneity in the use of the inputs is captured by the hospital specific productivity term, $w$ which depends on the HIS at the hospital. This is discussed in the next section. In essence, this function can be viewed as summing some technical health output production process over all patients.

The second constraint dictates how medical education is produced and without any loss of generality, the model assumes that the amount of health produced at the hospital, the severity of illness of patients, and the amount of labor devoted to education, $L^{e}$, all factor into its production.

The remaining two constraints involve demand for the hospital's services and the profit equation. Demand is considered to be a function of the population surrounding the hospital as well as the competitive environment that the hospital faces. These factors are labeled $X_{i t}$. Demand is also assumed to be a function of hospital quality which is observable (with noise) to patients and therefore determines the overall health output of the hospital. ${ }^{11}$

The profit equation involves two revenue terms and the usual cost terms. For all patients with some form of prospective payment insurance (PPS), be it an HMO or Medicare, the hospital's revenue is simply the reimbursement amount $R$. In contrast, fee-for-service (FFS) patients are charged some markup $\theta$ above the cost of their treatment, which is the sum of the labor ( $L$ is defined as the sum of labor used for health output and for education since they are assumed to be fully substitutable), capital and materials used, each multiplied by their respective input prices, $w$, $r$, and $m$.

\footnotetext{
${ }^{11}$ See Tay (2000) for recent evidence on how patients consider quality in making hospital decisions.
} 


\subsection{Empirical Specification}

The primary goal of the estimation is to examine the relationship between IT and variable cost, conditional on other relevant factors. The analysis is based upon regressing operating costs on several variables including the measures of IT and estimating the linear approximation to the conditional mean function for costs. The proper variables to include in this specification are identified from the model in the previous section.

For this purpose, functional forms for each of the above equations are not specified. Instead, the hospital's maximization problem is solved for the optimized values of $L$ and $M$ and then the results are inserted into a cost equation. Since this is a short-term cost specification, only labor and materials are considered in the hospital's control; capital is assumed fixed and cannot be altered. Substituting (2), (3), and (5) into (1) and then taking first order conditions, yields expressions for $L$ and $M$ as functions of the standard variables for a short-run cost function namely output, input prices, and capital as well as the insurance mix of the hospital's patients, their initial health status, the hospital's quality, and its unobserved productivity. In summary,

$$
V C_{i t}=V C\left(Y_{i t}, E_{i t}, w, m, K_{i t}, H_{i t}^{o} ; \omega_{i t}, \eta_{i t}\right)
$$

To incorporate IT into the model, $\omega_{i t}$, the hospital's productivity is specified as a function of some underlying productivity and the impact of information technology $S_{i t}$. In particular,

$$
\omega_{i t}=\omega_{i t}\left(\tilde{\omega_{i t}}, S_{i t}\right)
$$

This specification of IT as an exogenous component of productivity highlights its role as altering the use of other inputs, consistent with the prior discussion. Since IT is not formally modeled as a choice variable in the hospital's maximization problem, the actual costs of IT are not explicitly included either. This assumption has little effect however, since the model is being used solely to 
guide the empirical specification below.

Equations (6) and (7) form the basis for the estimation models. In particular, they specify the variables to be included in the regression equations predicting log variable cost conditional on IT. These include log output, log output squared, log input prices, capital, the case mix index and a series of variables designed to capture the IT status of the hospital. ${ }^{12}$ Specifically, the regression equations take the form:

$$
\begin{aligned}
\ln \left(V C_{i t}\right)= & \tau_{t}^{1}+\tau_{s}^{2} t+\beta_{1 t} L D I S_{i t}+\beta_{2 t} L D I S_{i t}^{2}+\beta_{3 t} L V T O T_{i t}+\beta_{4 t} L_{V T O T_{i t}^{2}+} \\
& \gamma_{t} L W A G E+\delta_{t 1} \text { FIXASSETS }_{i t}+\delta_{2 t} C M I_{i t}+\epsilon_{i t}
\end{aligned}
$$

where:

$$
\epsilon_{i t}=\alpha_{i}+f\left(S_{i t}\right)+\mu_{i t}
$$

In this specification, any impacts from IT are simply shifts in log costs. These shifts do not vary with output or any of the other covariates in this specification of the model. It is possible that coordination costs or excess resource use costs are higher as a percentage of costs at larger or more capital intensive hospitals. Yet without direct evidence that this is so, the model assumes that the percentage change in costs from IT use will not vary with output, capital, or case mix.

To capture industry wide changes in the hospital costs, two time variables are included. The first, $\tau_{t}^{1}$ is a series of time-specific dummies to capture overall shifts in the costs of hospital production. State-level trends, $\tau_{s}^{2}$ are also included to capture any heterogeneity in local demand conditions and/or state-varying regulations that may impact costs.

The hospital fixed effect captures all other variables from equation (6) that are not explicitly included in the estimation equation. These variables include the hospital's quality, its insurance mix, any unobserved productivity and the degree of teaching at the hospital. Over any long period

\footnotetext{
${ }^{12}$ The basic form of the estimation equation follows the recent panel cost function estimation by Carey (1997). Her work in turn builds on the prior studies by Grannemann, Brown and Pauly (1986) and Vita (1990). Clearly, these form a very small subset of the vast literature estimating hospital cost functions.
} 
of time, these variables are likely to vary substantially. However, the estimation covers a four-year interval, a time frame over which a 'fixed effect' is a reasonable assumption.

\subsection{Hospital Data}

The descriptive statistics for the variables in equations (8) and (9) can be found in Table 1, where all dollar figures have been converted to constant 1994 dollars using the GDP deflator. All variables refer to an entire hospital facility, not just to the inpatient acute care area. The unit of observation therefore includes associated clinics and other outpatient units. To the extent that information technologies in certain areas, such as the laboratory, will be used in all parts of the hospital, this definition allows us to capture all potential effects of IT.

As discussed earlier, the presence of IT may impact doctor's choices about whether patients are admitted or whether they are seen through a related facility. Again, using a broader definition of the hospital for costs will capture that impact. ${ }^{13}$

Variable costs are taken from the HCFA Hospital Cost Reports - Minimum Dataset and include all operating expenses net of capital and depreciation related costs. This definition of costs, dictated by the discussion of hospitals and the impact of IT, will capture any changes in variable costs due to changes in labor or materials use as the result of improved decision making, monitoring or lowered coordination costs. As discussed, changes from reductions or shifts in capital usage will not be measured.

The costs of information technology itself are included in this definition of costs for some hospitals as the data do not allow for their removal. Costs possibly captured in the data include IT labor, some licensing fees and smaller software purchases. Hospitals' capital expenditures for IT, which are likely to be much larger, are not included in these figures. The implications of this are fully discussed in the conclusion.

Defining output for a hospital is one of the most serious problems for studies of the health care industry. It is hard to find precise measures that capture the heterogeneous nature of the

\footnotetext{
${ }^{13}$ The great disadvantage of this approach is that there is no information on ambulatory systems in the data. While these are not widespread, omitting these from the analysis could introduce biases, assuming that the adoption of ambulatory systems is correlated with the adoption of other systems or with other right hand side variables.
} 
output produced by hospitals. In this study, two measures are utilized, namely inpatient discharges (LDIS) and outpatient visits (LVTOT). The data on inpatient discharges are taken from the HCFA Hospital Cost Reports - Minimum Dataset, while the outpatient visits are taken from the American Hospital Association Annual Survey of Hospitals. Neither inpatient discharges nor outpatient visits measures a homogeneous good, yet together they provide a rough quantity measure of the number of patients treated. ${ }^{14}$ The CMI index below captures the severity of illness variation among the inpatient population at each hospital

Table 1: Descriptive Statistics for IT and Non-IT Variables

\begin{tabular}{|c|c|c|c|c|c|c|c|c|}
\hline & 1987 & 1988 & 1989 & 1990 & 1991 & 1992 & 1993 & 1994 \\
\hline \multicolumn{9}{|l|}{ Non-IT Variables } \\
\hline Operating Cost(000's) & 48,164 & 53,507 & 58,293 & 63,227 & 69,736 & 75,609 & 78,776 & 81,179 \\
\hline Avg Hourly Wage & 14.239 & 14.911 & 16.204 & 17.475 & 17.976 & 18.536 & 18.966 & 19.310 \\
\hline Inpatient Discharges & 9,004 & 9,321 & 9,303 & 9,384 & 9,678 & 9,771 & 9,635 & 9,786 \\
\hline OutPatient Visits & 65,755 & 73,922 & 79,338 & 85,932 & 92,130 & 101,851 & 107,162 & 112,329 \\
\hline Fixed Assets(000's) & 31,378 & 33,291 & 35,227 & 36,366 & 39,163 & 40,469 & 42,872 & 44,551 \\
\hline Case Mix Index & 1.209 & 1.212 & 1.315 & 1.318 & 1.323 & 1.344 & 1.355 & 1.365 \\
\hline $\mathrm{N}$ & 2,852 & 2,764 & 2,712 & 2,808 & 2,603 & 2,706 & 2,654 & 2,589 \\
\hline \multicolumn{9}{|c|}{ Aggregate IT Measures } \\
\hline FCOUNT & 7.99 & 9.63 & 10.61 & 11.44 & 12.34 & 13.27 & 14.41 & 15.50 \\
\hline CCOUNT & 1.39 & 1.72 & 2.05 & 2.38 & 2.74 & 3.06 & 3.45 & 3.81 \\
\hline \multicolumn{9}{|c|}{ Grouped IT Measures } \\
\hline FINO & 960 & 625 & 438 & 329 & 208 & 132 & 67 & 29 \\
\hline FIN1 & 421 & 441 & 455 & 482 & 451 & 451 & 409 & 335 \\
\hline FIN2 & 705 & 937 & 1132 & 1357 & 1469 & 1536 & 1498 & 1384 \\
\hline FIN3 & 56 & 78 & 110 & 151 & 210 & 348 & 512 & 704 \\
\hline CLNO & 1645 & 1351 & 1113 & 971 & 748 & 646 & 510 & 388 \\
\hline CLN1 & 743 & 797 & 814 & 822 & 742 & 665 & 573 & 503 \\
\hline CLN2 & 440 & 577 & 732 & 938 & 1060 & 1227 & 1322 & 1376 \\
\hline CLN3 & 24 & 39 & 53 & 77 & 113 & 168 & 249 & 322 \\
\hline
\end{tabular}

Notes: All dollar values in 1994 dollars. Operating Costs are taken from the HCFA Hospital Cost Reports - Minimum Dataset and equal total operating expenses minus capital related costs for buildings and fixtures and for movable equipment. Fixed Assets and Inpatient Discharges are also taken from the Cost Reports. Average Hourly Wages and Case Mix Index are available from HCFA and publshed in the Federal Register. Data for Outpatient Visits is from the American Hospital Association Annual Survey of Hospitals.

There is just one price in this specification, namely the HCFA wage index for labor (LWAGE). This index, available from HCFA and published annually in the Federal Register is the average

\footnotetext{
${ }^{14}$ In studies more focused on hospital costs, various authors have used more refined output measures. See Grannemann et al. (1986) for one such paper.
} 
hourly wage in the hospital's MSA or NECMA divided by the national average hourly wage. These values are then multiplied by the national average hourly wage in each year to recover the regional wages. ${ }^{15}$ Since an adequate measure of materials prices is not available, they are currently omitted from the regressions. In essence, all hospitals are assumed to face the same non-labor prices with the time variables absorbing these effects.

The case mix variable (CMI) is a proxy for the initial health status of the patients. This variable, provided by HCFA, is an average of the values for each patient at each hospital and is designed to capture heterogeneity in the severity of cases within the hospitals.

\subsection{Measures of Information Technology}

The source of the IT data in this paper comes from the Dorenfest 3000+ Database, a new proprietary dataset of nearly 3,000 U.S. hospitals. The data was acquired from Sheldon Dorenfest and Associates, an IT and health care consulting firm in Chicago. This sample includes the complete census of non-federal hospitals in the U.S. with over 100 beds. Dorenfest surveyed this group annually from 1987 to 1995, asking each hospital questions about the hardware and software used for each of the many systems within the hospital. For this research, the 1987, 1990, 1993, and 1994 surveys are used and then smoothed to create a series of IT variables spanning the period. ${ }^{16}$ Thus, the data details for each year, the automation status of each application such as accounts payable or radiology, as well as the date the most current system was adopted. ${ }^{17}$

Table 2 details the applications included in the Dorenfest data along with the percentage of hospitals that had adopted each system by the given year. ${ }^{18}$ It is apparent that the adoption percentages vary widely across applications and over time. As an example, fewer than $1 \%$ of hospitals had clinical data repositories in 1987 while nearly $70 \%$ had patient registration systems. Over time, hospitals with laboratory systems increase from $31 \%$ in 1987 to over $75 \%$ by the end

\footnotetext{
${ }^{15}$ As the wage is included in log form, this adjustment has no effect on the results. It does however make the variables in Table 1 more meaningful.

${ }^{16}$ The Dorenfest data indicates the month and year of adoption for each application. As a result, one can infer the stock of applications in the intervening years. A system that is adopted and then updated or changed in between the observed years will be missed by this approach, yet this event is sufficiently unlikely to warrant much concern.

${ }^{17}$ The dataset also contains data regarding networking, firm IT strategy, hardware and software vendors, and more detail regarding certain systems. This data is not used in the current study.

${ }^{18}$ For the formal description used in gathering the data for each application, see Borzekowski (2002).
} 
of the sample. It is this extreme variation in the data that allows us to look at the correlation between IT adoption and costs.

To capture the degree of automation of the hospital, three different sets of IT variables are created and used separately. While all are derived from the application data previously discussed, each is designed to answer a different and important question. The count based measures examine the cost effects from the overall level of automation. In contrast, the individual application measures attempt to isolate the way these costs may change, while the grouped measures look for complementarities across systems.

All three regressions utilize lags of the IT variables. Since there are substantial learning curves for IT (Brynjolfsson and Hitt 2000), contemporaneous measures of automation are unlikely to yield interesting results. Instead, the lagged presence of automation is used as the independent variable. In particular, lags of one, three and five years are included. These capture short, medium and longer term associations between IT and costs in a simple and flexible way. Adding the other lags would add little to the analysis and would limit the precision of the estimates.

The lags are limited to a five year maximum to mitigate one other problem in the data. In some instances, only how long a given hospital has had its then current system is known. If that hospital was not present in a prior sample or if that application was not part of a prior survey, one cannot determine whether that task was automated prior to the adoption of the current system. Dropping such cases would greatly limit the sample. Furthermore, it would create sampling issues as only those hospitals without recent upgrades would be included. To be conservative, the analysis assumes that the system was not there prior to the given adoption date. For many hospitals and systems this will be correct; for others, it assumes a recent adoption where none is present, and as such, dilutes any discernable impacts of adoption. Note, using only four years of data in the estimation further mitigates this problem.

The first IT measure is an aggregate index of the degree of automation in each domain at each hospital at each point in time. This index is meant to capture the overall amount of computing that is happening within the organization, not by the cost of hardware, but rather by the number of functional and cross functional areas that are automated. The justification for using such a count 
Table 2: Structure and Penetration of Hospital Information Systems: 1987-1994

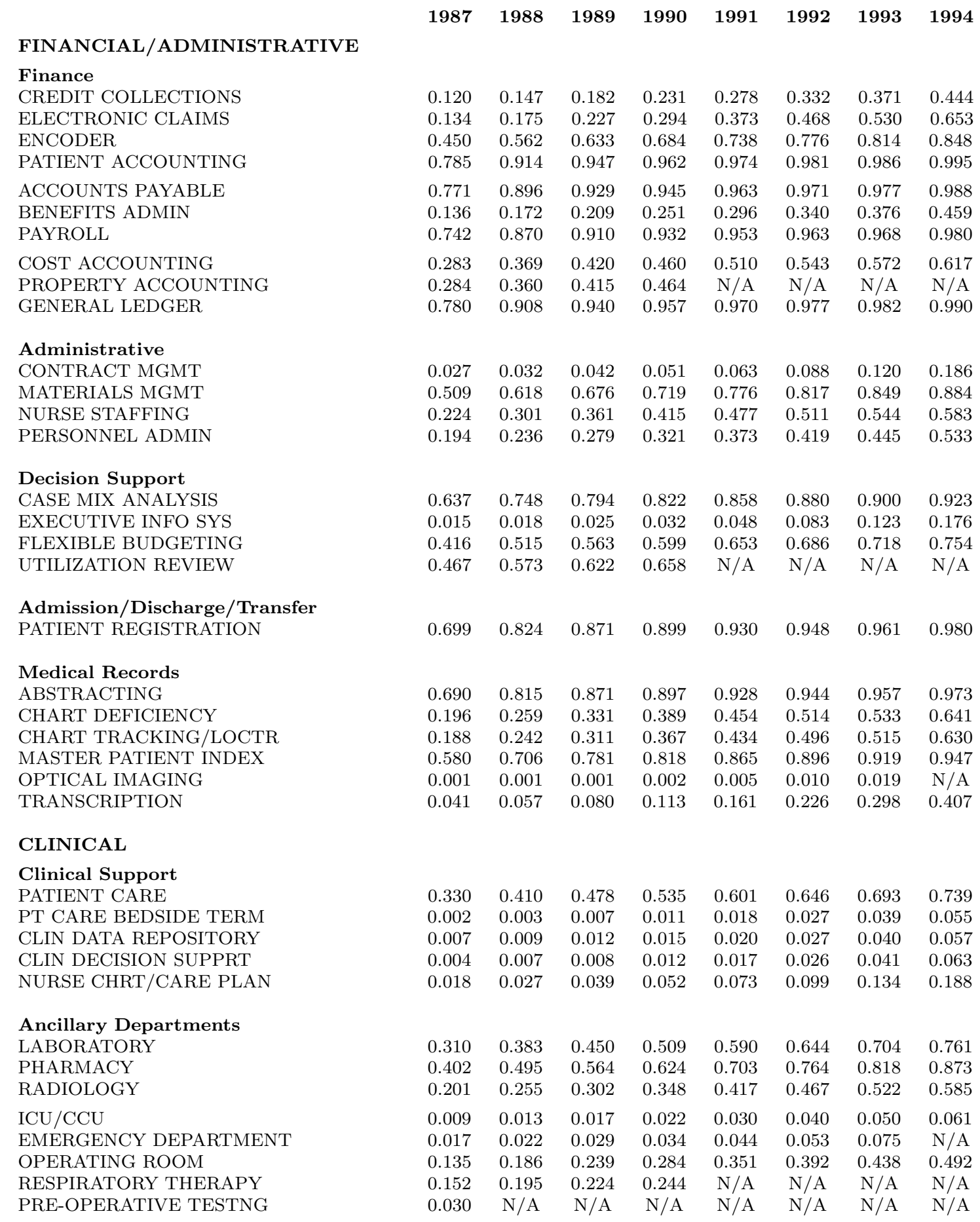

Notes: Entries detail the percentage of U.S. hospitals with more that 100 beds who indicated using the given application in the given year. This data is based upon the entire sample of 3307 hospitals in the Dorenfest database. N/A indicates that the application was no longer being tracked by Dorenfest. 
measure lies in the specific structure of these systems. Hospitals automated their organizations one department at a time, following the strict organizational boundaries within the firm. As such, it is quite reasonable to measure IT in this setting by asking which areas are automated or by counting 'how much' of the hospital is automated at a given hospital. In other type of organizations, this counting approach may be less reasonable, however it seems a logical metric in this case.

Another advantage of examining application-level data when studying hospitals is the prevalence of outsourcing. In the earlier years of the sample, the percentage of hospitals utilizing off-site systems ranges from about 9-10\% for most clinical applications to over $40 \%$ for many of the financial/administrative applications. While clearly lower at the end of the period, a significant fraction of hospitals still utilized off-site computing. In any industry with extensive IT outsourcing, hardware based measures are likely to underestimate the value of IT investment. Highly automated hospitals with outsourced IT will appear to have zero or no hardware stock. However, these same hospitals may exhibit lower costs or higher quality. As a result, regressing costs on just the hardware measure of IT will skew the results toward overstating IT's impact.

The precise bases for the indices used in the analysis are counts of the number of finance systems (FCOUNT) and clinical systems (CCOUNT) at each point in time. These variables are described in Table 1. By 1991, hospitals had adopted an average of 12.34 financial applications and 2.74 clinical applications. These numbers are increasing at approximately one new financial application per year and one new clinical application every three years over the sample period. Throughout these years, the number of possible financial applications is fixed at twenty-two and the number of clinical applications at ten. ${ }^{19}$

To use these variables as indices, linear and quadratic terms are included for each count. Since the functional form of the true relationship between IT and costs is unknown, this second-order polynomial is simply an approximation. Additional higher order terms would increase the flexibility of the specification at the cost of precision. In fact, attempts to estimate cubic terms were unable to yield significant results. Restricting the specification to only linear terms would limit the marginal

\footnotetext{
${ }^{19}$ In creating these measures, only applications for which data is available over the entire period are counted. This limits the number from 38 to 32 since property accounting, utilization review, optical imaging, emergency room, respiratory therapy and pre-operative testing are dropped.
} 
relationship between IT and costs to be constant. The quadratic specification seems to strike the correct balance. Formally, $f\left(S_{i t}\right)$ from equation (9) is defined as:

$$
f_{1}\left(S_{i t}\right)=\sum_{l=1,3,5}\left(\lambda_{1 l} F C O U N T_{i t-l}+\lambda_{2 l} F C O U N T_{i t-l}^{2}+\right.
$$

$$
\left.\lambda_{3 l} C C O U N T_{i t-l}+\lambda_{4 l} C C O U N T_{i t-l}^{2}\right)
$$

A second set of IT variables is used to isolate the potential impact of individual systems. In this set, $f\left(S_{i t}\right)$ is a vector of dummy indicators for the presence or absence of each application in each year. Including such a long list of variables (together with their lags) introduces nearly 100 coefficients to be estimated, yet this is the least restrictive way to use the richness of the available data. Define $I_{i a t}$ as an indicator variable that takes the value 1 if hospital $i$ has application $a$ at time $t$. Then, $f\left(S_{i t}\right)$ is defined as:

$$
f_{2}\left(S_{i t}\right)=\sum_{l=1,3,5} \sum_{a} \lambda_{a l} I_{i t-l}
$$

As explained earlier, finding significant cost effects from individual systems may not only answer the question about IT's overall impact, but may also shed light on the underlying mechanism by which IT can lower costs. As an example, were medical records applications to be associated with the greatest costs decrease, one could argue for reduced administrative cost. In contrast, a finding that more clinical systems were associated with reduced costs opens the possibility that improved decision making or more monitoring is the pathway.

The last set of variables is an attempt to lower the dimensionality of the regressor set and to incorporate the idea that complementarities may exist across IT applications. ${ }^{20}$ Evidence exists to indicate that productivity gains from IT may only result from the automation of several tasks

\footnotetext{
${ }^{20}$ Ichniowski, Shaw and Prennushi (1977) use a similar approach in their work examining productivity impacts from groups of human resource management practices. They do however, use more rigorous statistical tests to group the independent variables.
} 
combined with a restructuring of the work flow process. To capture this, the hospitals are grouped into four financial groups and four clinical groups depending on their level of automation. The first financial group (FINO) includes those hospitals utilizing only 'older' applications - applications that have diffused to over $60 \%$ of hospital's by $1990 .{ }^{21}$ These applications automate basic transactions within the hospital and have little analytic capability. The next group (FIN1) include hospitals utilizing some newer applications but not cost accounting systems, financial management systems, executive information systems (EIS) or contract management systems (CONM). These hospitals are more advanced than the first group, but still limited in their use of IT. The third group (FIN2) includes those that have either cost accounting or financial management systems but not the more advanced EIS or CONM applications. With these systems in place, the hospital has started to use IT strategically and to go beyond the automation of transactional activities. Such applications signal an attempt to use IT to gather data for decision making and to gather more strategic information. The last group (FIN3) consists of hospitals that have adopted executive information systems or contract management systems. These hospitals are clearly at the forefront of IT automation. The number of hospitals in each group in each year is detailed in Table 1.

The divisions on the clinical side are derived in a similar but even more specific manner. Here, the first group $(C L N O)$ are those with zero or one automated ancillary department and no use of a patient care system or a clinical data system (BST, CLDS or CLDR). These hospitals are clearly at the onset of automating their clinical domain. In the second group (CLN1) are those hospitals with two or three of the ancillary applications who are not running any of the more advanced systems as well as those hospitals with a patient care system and only zero or one ancillary systems. Patient care systems link the wards to the ancillary departments, and therefore, hospitals with such systems are the most likely to have started reworking the health care provision process. The third group (CLN2) are further along this process and include those hospitals with two or three ancillary systems and a patient care system. The last and most automated group (CLN3) are those with any of the clinical support systems installed. As with the last group in the financial arena, these hospitals have the capacity to use the data more strategically and gather newer and more varied

\footnotetext{
${ }^{21}$ These nine applications include encoder, patient accounting, payroll, accounts payable, general ledger, materials management, case mix analysis, patient registration and abstracting.
} 
data from their systems.

In summary, the last definition for $f\left(S_{i t}\right)$ is simply:

$$
f_{3}\left(S_{i t}\right)=\sum_{l=1,3,5} \sum_{k=0}^{3}\left(\lambda_{f k l} F I N k_{i t-l}+\lambda_{c k l} C L N k_{i t-l}\right)
$$

\section{Results}

This section presents the results of the three basic regressions. The non-IT variables are the same in each regression. The basic form of the IT variables is also the same regardless of the IT measure used and includes three lags corresponding to one year, three years and five years. However, to calculate the cumulative effect of having adopted a given system or having moved into a newer status, requires the summation of the relevant coefficients from the regression. To see this, consider a hospital that adopted a new system at t-3. By construction, it also had that system at t-1 and as a result the relationship to costs three years after adoption is the sum of these two coefficients. It is this cumulative effect that is listed in each table.

\subsection{Regression using Aggregate Indices}

The results of the first regression can be found in Table 3. The first panel of the table displays the coefficients on the output, wage, capital, and case mix variables. The second panel shows the coefficients for the cumulative impact of the IT systems summed over the lags.

To begin, note that all of the non-IT variables have the expected sign. As expected, costs are predicted to increase with increases in output, wages, and illness severity.

The trends in these variables are also interesting. For most of the variables, the coefficient estimates are significantly different from year to year. The year dummies capture the rapidly increasing national trend in hospital costs, and while not reported, the state-level linear time trend is significant for approximately one-third of the states.

The coefficients on inpatient discharges are increasing, while the coefficients on outpatient visits are decreasing over time. The former result reflects the increasing shift of patients, for both 
technological and economic reasons, away from inpatient care toward less costly alternatives. The result is that those that are hospitalized are sicker and more costly to treat.

Table 3: Results from Fixed Effect Model Using Aggregate Indices

\begin{tabular}{|c|c|c|c|c|}
\hline \multicolumn{5}{|c|}{ Coefficients for Non-IT Variables } \\
\hline Variable & 1991 & 1992 & 1993 & 1994 \\
\hline $\mathrm{C}$ & & $.3910(.0654)^{* * *}$ & $.6305(.0821)^{* * *}$ & $.8689(.1044)^{* * *}$ \\
\hline LWAGE & $.1387(.0656)^{* *}$ & $.0591(.0656)$ & $.0356(.0657)$ & $-.0076(.0666)$ \\
\hline LDIS & $.6246(.0108)^{* * *}$ & $.6343(.0109)^{* * *}$ & $.6944(.0105)^{* * *}$ & $.6831(.0105)^{* * *}$ \\
\hline LDIS2 & $-.0070(.0033)^{* *}$ & $-.0186(.0034)^{* * *}$ & $-.0062(.0028)^{* *}$ & $-.0162(.0032)^{* * *}$ \\
\hline LVTOT & $.0519(.0120)^{* * *}$ & $.0214(.0129)^{*}$ & $.0280(.0118)^{* *}$ & $.0045(.0133)$ \\
\hline LVTOT2 & $-.0119(.0030)^{* * *}$ & $-.0028(.0032)$ & $-.0037(.0029)$ & $.0045(.0031)$ \\
\hline LFIXASS & $.0617(.0060)^{* * *}$ & $.0468(.0065)^{* * *}$ & $.0219(.0061)^{* * *}$ & $.0232(.0061)^{* * *}$ \\
\hline CMI & $.2289(.0326)^{* * *}$ & $.2112(.0319)^{* * *}$ & $.1448(.0319)^{* * *}$ & $.1085(.0313)^{* * *}$ \\
\hline \multicolumn{5}{|c|}{ Cumulative Impact from Adoption at Various Lags } \\
\hline Variable & $\mathrm{t}-1$ & $\mathrm{t}-3$ & $\mathrm{t}-5$ & \\
\hline FCOUNT & $.0030(.0027)$ & $.0077(.0033)^{* *}$ & $.0131(.0035) * * *$ & \\
\hline FCOUNT2 & $-.0001(.0001)$ & $-.0003(.0001)^{* *}$ & $-.0007(.0002)^{* * *}$ & \\
\hline CCOUNT & $.0027(.0048)$ & $.0030(.0065)$ & $.0071(.0078)$ & \\
\hline CCOUNT2 & $-.0009(.0006)$ & $-.0015(.0009)$ & $-.0023(.0011)^{* *}$ & \\
\hline
\end{tabular}

Notes: Standard Errors are in parentheses. ${ }^{*}$ denotes significance at the 10-percent level, ${ }^{* *}$ at the 5-percent level, and ${ }^{* * *}$ at the 1-percent level. Regression also includes variables for hospital level fixed effects as well as state level trends.

The wage coefficient, as well as the case mix index and fixed assets coefficients, are all declining over the observed period. The wage coefficient is rarely significant as the state-level time trends are capturing the differences in wages across states. This is a direct result of the HCFA wage definition which assigns the same wage to the entire non-MSA area of a state. The case mix variable should decline in importance as it measures only inpatient severity of illness. As a greater percentage of costs is due to outpatient activities, this coefficient should decrease over time. At this time, few explanations exist for the asset coefficients.

The IT variable coefficients show an unexpected pattern. For both financial and clinical systems the linear terms are positive while the quadratic terms are all negative. For financial systems, both the linear and quadratic coefficients are significant for the longer lags. The results for the clinical applications are less precisely estimated.

Taken literally, the coefficients on the IT variables capture the correlations between variable costs and the prior stock of applications and between costs and the stock of applications squared. They can be interpreted as the marginal effect, ceteris paribus, of adopting a new application. 
However, the inclusion of the squared terms implies that this marginal effect of increasing the number of applications depends upon the point at which the effect is measured.

To see this clearly, the results are displayed graphically in Figure 1. The first panel charts the marginal change in costs from an additional financial system while the second panel does the same for clinical systems. These are simply the first derivatives of the function in Equation 8 with respect to FCOUNT and CCOUNT respectively. The marginal effects are linear since the model is specified as quadratic. For both types of systems and at all lags, the marginal predicted change in costs is positive for hospitals with limited number of applications already automated while it is negative for the most automated hospitals.

As a specific example, examine the marginal change in log costs three years after the adoption of a financial/administrative system. For a hospital with fifteen financial applications, the addition of an additional system is associated with a $.2 \%$ reduction is costs. In contrast, costs are $.2 \%$ higher three years after adopting an additional system for a hospital with only nine financial applications. The pattern is similar for clinical systems yet the magnitudes are larger for the most automated hospitals.

Examining the lag structure, it is apparent that any changes in costs related to IT emerge several years after adoption. For the financial systems, the coefficients are significantly different from zero only for the three and five year lags. Only the five year lags are significant for the clinical systems. Furthermore, the associations between cost and IT grow stronger over time, as evidenced by the steepening of the lines in both figures. For a given stock of applications, having adopted an additional system five years ago has a greater impact on predicted costs than having adopted that same system just one year ago.

The results for less automated hospitals are the most surprising. The association of HIS adoption with both higher and rising costs for these hospitals raises concerns about the estimation results. In particular, it raises the possibility that differences in costs seemingly associated with HIS may in fact be caused by some other factor that is also driving IT adoption. The fixed effects in the model capture any possible correlation of costs and IT to time-invariant hospital effects. Similarly, the inclusion of the state-level trends captures any time-varying state-level effects that would drive 
Figure 1: Relationship of Log Variable Cost to Changes in Number of Applications

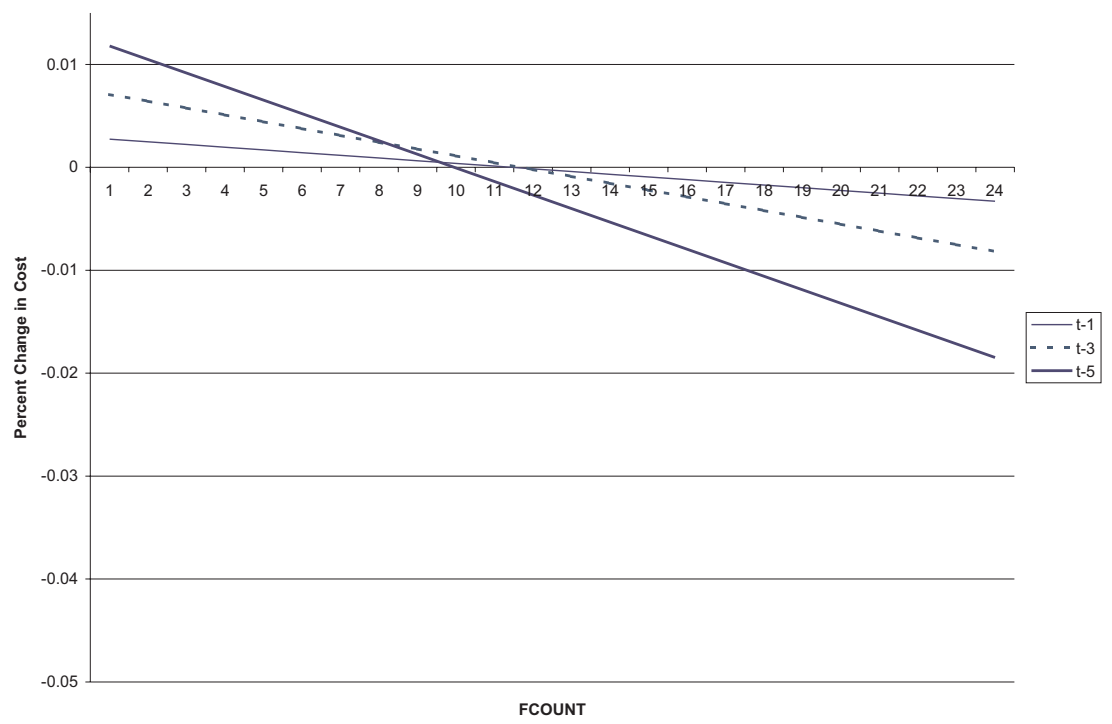

Panel 1: Graphs detail the marginal change in predicted costs from an additional financial/administrative system as a function of the number of systems already installed at the hospital.

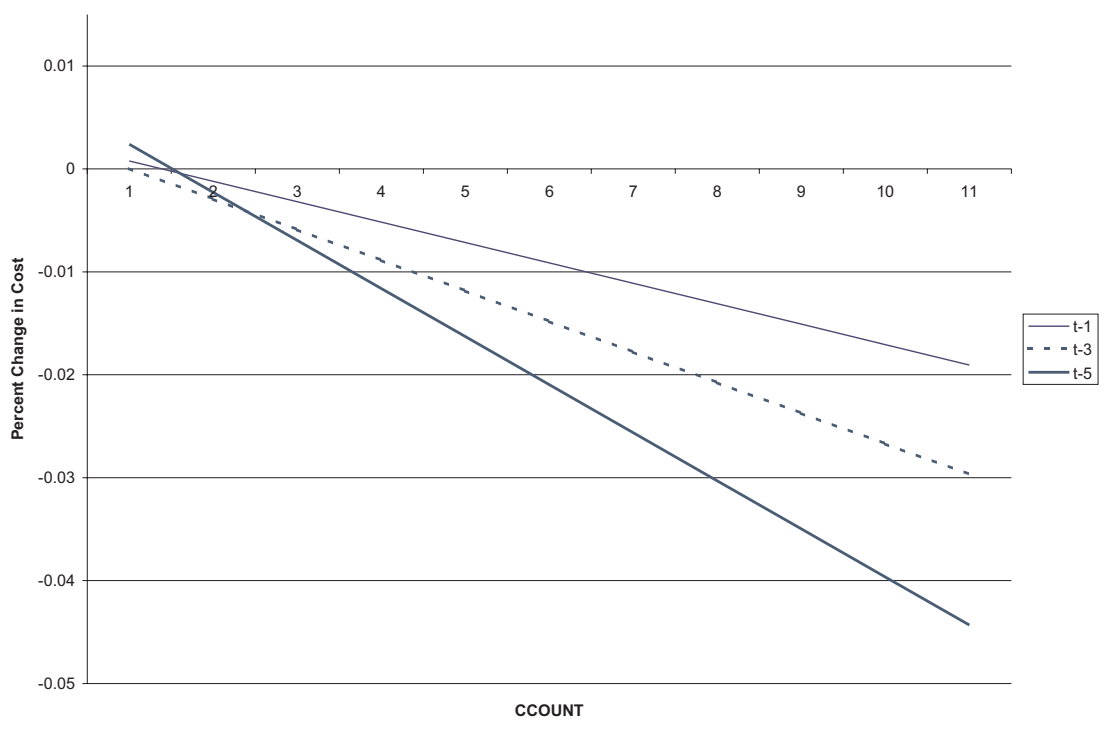

Panel 2: Graphs detail the marginal change in predicted costs from an additional clinical system as a function of the number of systems already installed at the hospital. 
both IT and costs. The open possibility is that some hospital-specific time-varying effect may be driving both variables. To examine the issue further, additional analyses were done.

One possible explanation for the results showing increasing predicted costs after HIS adoption from one to three to five years later may be the quadratic specification. The empirical model restricts the marginal effects to being linear; as a result, in order to capture the declining costs for the more automated hospital, the model will show costs to rise at the less automated hospitals.

To test this, freer models including cubic terms were also run. In those results, not reported here, costs at the less automated hospitals still rise after adoption but do not increase. Instead, the results for the financial applications show a slight increase in costs for less automated firms that does not shift much over time. Costs at the more automated hospitals continue to show declines associated with HIS, similar to the prior results. For clinical systems, none of the coefficients are precisely estimated and as a result, the curves are very noisy. In sum, the looser specifications provide some evidence that the original estimation may be too restrictive and that in fact, cost are not rising post adoption for these hospitals.

To further examine the possibility of an unobserved hospital-specific cost trend that accounts for both the HIS adoption and the changes in costs, lead regressions were done. In these regressions, future IT levels are included to predict current costs. If unobserved time-varying effects are driving both, then these variables should be able to explain current costs. In fact, they do not. None of the coefficients on future IT are found to be significant. Again, this is taken as further evidence against the idea of unobserved time-varying hospital-specific effects.

With the evidence from the estimations included in this study and the other checks that were done, it appears unlikely that unobserved effects are driving the IT results. Instead, it does appear that at more automated hospitals, HIS adoption is associated with lower operating costs. At less automated hospitals, costs rise a bit after adoption, most likely as a result of organizational disruptions and learning effects. A complete discussion of these issues is deferred until section 5 . 


\subsection{Regression using Application Indicators}

The results for the application indicator regressions are in Table 4. In this analysis, dummies for each of the 32 applications (22 financial/administrative, and 10 clinical) are included. The other parts of the regression equation are unchanged from the previous analysis. For space considerations, Table 4 includes only those applications with significant results among any of the three lags.

The coefficients for the non-IT variables are largely unchanged from the first regressions and warrant little attention. The IT variables again present interesting results. If one examines the systems on a functional level, several applications at the leading edge of technology are correlated with declining costs. In the financial domain, these include cost management systems as well as systems used to administer managed care contracts. In the former case, the adoption of cost management systems is most likely an indicator of a larger program within the organization to focus on costs. As discussed earlier, most gains from IT adoption arise when the technology is tied to other organizational changes. Cost management systems are a part of this larger effort which as a whole is associated with reduced costs.

For contract management systems, it is possible that the IT systems have allowed hospitals to save on costs; however, it is also possible that this is a selection effect. Hospitals in areas of rapidly increasing managed care penetration might be those with declining costs; they may also be the hospitals most likely to adopt managed care systems. At present, the data cannot distinguish between these explanations.

While several of the applications do appear to lead to lowered costs, several others are associated with increased variable costs. These include payroll, materials management, and flexible budgeting, all of which are well-diffused applications by 1991. Hospitals adopting these systems are most likely at the early stages of automation and therefore still incurring the organizational learning costs needed to use these technologies effectively. This is the same result seen in the aggregate results discussed earlier.

The dynamics at the application level appear quite similar to those from the aggregate regressions. For almost all of the applications, the associations with cost (either negative or positive) are stronger at five years after adoption than at one year. As an example, the presence of a radiology 
system predicts a reduction of just about $1 \%$ of costs in the year following adoption. This grows to over $3 \%$ after five years. The cumulative effect of contract management systems more than doubles from $2.8 \%$ to over $6 \%$. Even systems that are positively correlated with costs, such as payroll and flexible budgeting, display this pattern. Only clinical decision support systems and materials management systems have cost effects that appear to lessen over time. In sum, this confirms the original idea that IT impacts are lagged and that instantaneous results are unlikely.

Table 4: Results from Fixed Effect Model Using Application Indicators

\begin{tabular}{|c|c|c|c|}
\hline \multicolumn{4}{|l|}{ Coefficients for Non-IT Variables } \\
\hline Variable & 1992 & 1993 & 1994 \\
\hline $\mathrm{C}$ & $.3965(.0656)^{* * *}$ & $.6307(.0825)^{* * *}$ & $.8713(.1052)^{* * *}$ \\
\hline $.1270(.0661)^{*}$ & $.0479(.0661)$ & $.0267(.0662)$ & $-.0140(.0671)$ \\
\hline $.6308(.0108)^{* * *}$ & $.6384(.0110)^{* * *}$ & $.6959(.0105)^{* * *}$ & $.6845(.0106)^{* * *}$ \\
\hline$-.0054(.0033)$ & $-.0175(.0034)^{* * *}$ & $-.0059(.0028)^{* *}$ & $-.0161(.0032) * * *$ \\
\hline $.0523(.0121)^{* * *}$ & $.0219(.0130)^{*}$ & $.0271(.0118)^{* *}$ & $-.0016(.0134)$ \\
\hline$-.0119(.0030)^{* * *}$ & $-.0028(.0032)$ & $-.0036(.0029)$ & $.0050(.0031)$ \\
\hline $.0610(.0061)^{* * *}$ & $.0469(.0065)^{* * *}$ & $.0224(.0059)^{* * *}$ & $.0230(.0062)^{* * *}$ \\
\hline $.2360(.0331)^{* * *}$ & $.2165(.0320)^{* * *}$ & $.1533(.0320)^{* * *}$ & $.1146(.0315)^{* * *}$ \\
\hline \multicolumn{4}{|c|}{ Cumulative Impact from Adoption at Various Lags } \\
\hline Variable & $\mathrm{t}-1$ & $\mathrm{t}-3$ & $\mathrm{t}-5$ \\
\hline ENCODER & $-.0090(.0076)$ & $-.0187(.0105)^{*}$ & $-.0259(.0132)^{* *}$ \\
\hline BENEFITS ADMIN & $-.0078(.0101)$ & $-.0184(.0156)$ & $.0547(.0203)^{* * *}$ \\
\hline PAYROLL & $.0320(.0164)^{*}$ & $.0457(.0198)^{* *}$ & $.0552(.0221)^{* *}$ \\
\hline COST ACCOUNTING & $-.0150(.0083)^{*}$ & $-.0278(.0112)^{* *}$ & $-.0493(.0134)^{* * *}$ \\
\hline CONTRACT MGMT & $-.0269(.0099)^{* * *}$ & $.0341(.0178)^{*}$ & $-.0690(.0247)^{* * *}$ \\
\hline MATERIALS MGMT & $.0127(.0074)^{*}$ & $-.0034(.0101)$ & $.0066(.0125)$ \\
\hline PERSONNEL ADMIN & $.0087(.0098)$ & $.0162(.0148)$ & $.0368(.0192)^{*}$ \\
\hline EXECUTIVE INFO SYS & $.0018(.0084)$ & $.0029(.0174)$ & $-.0547(.0272)^{* *}$ \\
\hline FLEXIBLE BUDGETING & $.0104(.0083)$ & $.0253(.0111)^{* *}$ & $.0286(.0134)^{* *}$ \\
\hline ABSTRACTING & $-.0345(.0120)^{* * *}$ & $-.0338(.0149)^{* *}$ & $-.0445(.0175)^{* *}$ \\
\hline MASTER PATIENT INDEX & $.0385(.0098)^{* * *}$ & $.0555(.0128)^{* * *}$ & $.0667(.0158)^{* * *}$ \\
\hline CLIN DECISION SUPPORT & $-.0390(.0154)^{* *}$ & $-.0338(.0308)$ & $-.0196(.0488)$ \\
\hline RADIOLOGY & $-.0100(.0068)^{*}$ & $-.0187(.0099)^{*}$ & $-.0314(.0129)^{* *}$ \\
\hline
\end{tabular}

Notes: Standard Errors are in parentheses. ${ }^{*}$ denotes significance at the 10 -percent level, ${ }^{* *}$ at the 5percent level, and $* * *$ at the 1-percent level. While all 32 applications were included in the estimation of this regression, only those where one or more of the cumulative IT coefficients were significant are shown in the table. Regression also includes variables for hospital level fixed effects as well as state level trends.

A second way to examine the data is to group systems by the mechanism by which each may impact costs. In these results, systems designed to go beyond the automation of transactions (i.e. those systems that gather, store and present information in a such a way that it aids new types of 
decision making) are associated with declining variable costs. This result is true in both domains. Within the financial/administrative domain, executive information systems are associated with lower costs after a lag of five years. In the clinical domain, clinical decision support systems have an almost immediate effect which continues over the full five years. These results may again indicate selection effects where hospitals with declining costs are free to experiment with the latest tools, yet these systems may also help to directly lower hospital costs.

Regarding the remaining systems with significant results, the interpretations are less obvious. The contradictory findings on the two medical records systems seem the most troubling, yet few insights explain this result.

\subsection{Regression using Status Groupings}

The major drawback of examining IT's impact on a system by system basis is that it may miss cumulative effects that rely on the adoption of a set of IT systems. To look for such effects, the four groupings defined in the previous sections are used as the last set of IT regressors. The results for these regressions can be found in Table 5. The three variables in each section are dummy variables for the three highest level groups (FIN1 - FIN3, CLN1 - CLN3); the omitted category includes those hospitals with the least technology deployed. Again, the first panel of Table 5 includes the non-IT variables and the second panel includes the cumulative IT effects. As with the prior tables, the raw coefficients on the IT variables are omitted from the chart.

As expected, the non-IT results are nearly unchanged from the prior regressions. The IT variables mimic the prior results as well. Those hospitals moving from FIN0 to FIN1 seem to have higher costs after adoption while those moving from FIN2 to FIN3 are seeing lower costs. This result may be capturing the same effects previously seen.

On the clinical side, the patterns for the cumulative effects, while not significant, also parallel the aggregate results. Moving to CLN1 is associated with an increase in costs while moving to CLN2 and then to CLN3 is associated with decreased costs. The only significant effect is the short term impact of moving to $C L N 3$ which is most likely capturing the same effects seen in the previous regression from adopting a clinical decision support system. 
Table 5: Results from Fixed Effect Model Using Status Groupings

\begin{tabular}{|c|c|c|c|c|c|}
\hline \multicolumn{6}{|c|}{ Coefficients for Non-IT Variables } \\
\hline Variable & 1991 & 1992 & & 1993 & 1994 \\
\hline $\mathrm{C}$ & & $.3931(.0647)^{* * *}$ & .6329 & $(.0814)^{* * *}$ & $.8650(.1037)^{* * *}$ \\
\hline LWAGE & $.1553(.0651)^{* *}$ & $.0738(.0651)$ & .0490 & $(.0652)$ & $.0079(.0661)$ \\
\hline LDIS & $.6310(.0107)^{* * *}$ & $.6364(.0109)^{* * *}$ & .6937 & $(.0104)^{* * *}$ & $.6817(.0105)^{* * *}$ \\
\hline LDIS2 & $-.0067(.0032)^{* *}$ & $-.0187(.0034)^{* * *}$ & -.0066 & $(.0028)^{* *}$ & $-.0166(.0031)^{* * *}$ \\
\hline LVTOT & $.0505(.0117)^{* * *}$ & $.0229(.0125)^{*}$ & .0295 & $(.0115)^{* *}$ & $.0043(.0130)$ \\
\hline LVTOT2 & $-.0117(.0030)^{* * *}$ & $-.0031(.0031)$ & -.0041 & $(.0028)$ & $.0043(.0031)$ \\
\hline LFIXASS & $.0629(.0059)^{* * *}$ & $.0492(.0064)^{* * *}$ & .0245 & $(.0058)^{* * *}$ & $.0240(.0061)^{* * *}$ \\
\hline CMI & $.2339(.0326)^{* * *}$ & $.2142(.0315)^{* * *}$ & .1491 & $(.0315)^{* * *}$ & $.1136(.0307)^{* * *}$ \\
\hline \multicolumn{6}{|c|}{ Cumulative Impact from Adoption at Various Lags } \\
\hline Variable & $\mathrm{t}-1$ & t-3 & & $\mathrm{t}-5$ & \\
\hline FIN1 & $.0167(.0079)^{* *}$ & $.0189(.0110)^{*}$ & .0214 & $(.0136)$ & \\
\hline FIN2 & $.0070(.0066)$ & $.0110(.0092)$ & .0089 & $(.0119)$ & \\
\hline FIN3 & $-.0078(.0087)$ & $-.0173(.0150)$ & -.0588 & $(.0224)^{* * *}$ & \\
\hline CLN1 & $.0003(.0073)$ & $.0027(.0098)$ & .0134 & $(.0120)$ & \\
\hline CLN2 & $-.0050(.0083)$ & $-.0124(.0117)$ & -.0078 & $(.0149)$ & \\
\hline CLN3 & $-.0270(.0122)^{* *}$ & $-.0289(.0203)$ & -.0284 & $(.0293)$ & \\
\hline
\end{tabular}

In general, the striking similarity between these results and the more aggregate results from the first regression call into question the specific groupings used to create the measure. It may still be true that particular groups of applications, when used together, lower costs. The current groupings, however, do not demonstrate such a result.

\subsection{Comparison of Regressions}

Taken together, the results of these three regressions point to two general conclusions. First, IT is associated with lower costs at the most automated hospitals. Second, the adoption of particular systems is also associated with lower costs. These two findings are distinct. The first points to an aggregate effect; upon reaching a critical level of automation, IT may help to lower costs. The second points to the impact of particular systems.

To see how these facts are distinct, consider a situation where all hospitals adopt systems A, $\mathrm{B}$, and $\mathrm{C}$, in that order and that together systems $\mathrm{B}$ and $\mathrm{C}$ will lower costs for the hospital. In this case, the aggregate regressions would show a negative coefficient on IT and the applicationlevel regressions would show a negative coefficient for system C. Here, the same effect, namely the 
benefits from the $\mathrm{B}$ and $\mathrm{C}$ combination, is being picked up by both analyses.

In reality, all hospitals are not adopting systems in the same order. Hospitals vary in the order in which they adopt certain systems. As an example, only $39 \%$ of hospitals with a cost accounting system in 1987 had also adopted flexible budgeting, while nearly 90\% had adopted a general ledger system. Only $46.7 \%$ of hospitals with a pharmacy system had already adopted a laboratory system. Were all hospitals to adopt IT systems in a given order, all of these values would be $0 \%$ or $100 \%$.

As a result, the first two regressions provide different information. The application-level regressions show that certain systems and types of systems are associated with lower costs in the years following adoption. As well, in the aggregate, the adoption of any additional system is associated with lower costs at the most automated hospitals. This last result opens the possibility of complementarities between systems (i.e. the presence of some IT increases the marginal return to the adopted systems), although the results using the current status groupings cannot confirm this.

\section{Conclusion}

Several features of hospitals and hospital information systems limit the applicability of traditional hardware based measures of IT and encourage an application based framework. This research takes advantage of the system-by-system structure of HIS, as well as a rich dataset of nearly 3000 hospitals to create new application-based measures and to assess whether IT is associated with lower hospital costs during the early 1990's.

In all three of the analyses, there is evidence that hospitals adopting 'newer' applications have had lower costs. On a functional level, hospitals utilizing cost management, contract management, or radiology systems have seen falling costs since adoption. In the aggregate, adoption of any additional systems by more IT advanced hospitals is associated with declining costs.

Further, there is evidence that systems which provide decision makers newer and more tailored information are also associated with lower costs. In her book, In the Age of the Smart Machine, Soshana Zuboff labels such systems as 'informating' and contrasts them with technologies that simply automate routine tasks (Zuboff 1988). The current data provides no evidence that this 
latter group of systems is associated with any cost changes.

The approach in this study was targeted to assess primarily the direction of any association between HIS and operating expenses rather than the magnitude. Nevertheless, the magnitudes from these analyses offer an optimistic picture. The adoption of additional financial systems at more automated hospitals is associated with 1-2\% lower operating costs five years after adoption. Clinical systems are associated with declines of 3-5\%, five years later. As these estimates ignore changes in fixed costs, they form a lower bound on IT's effects on total costs.

To interpret these savings and to compare them to the costs of IT requires some assumptions about the IT expenditures that may still be included in the data. As discussed earlier, capital related costs are omitted from the dependent variable, while some ongoing costs related to IT are still included. Depending on the pattern of these costs, the savings that seem to be evident may or may not be real.

To see this, imagine that the costs used in the estimation reflect one time costs that are spent at adoption and during the two years after, but then cease. In this scenario, the reduction in costs associated with adoption that appears three years later may simply be the elimination of these system costs rather than savings. However, if the IT expenditures that are included in the variable cost measure are reasonably consistent at a given hospital, the visible cost reductions must be associated with the IT change. This latter scenario is far more likely given other data sources about IT expenditure - thus offering the possibility that savings are real.

For a rough estimate of the relationship between IT and total cost, one can compare the costs of IT to the predicted savings from the model. During this period, hospitals spent approximately 2-3\% of annual operating expenses on IT. From the data used in this study, it appears that this corresponded to adopting a new financial system approximately once a year and a new clinical system every three years. As such, it appears that the costs savings associated with HIS adoption should create net savings, however more detailed calculations would be needed. ${ }^{22}$ In particular, one needs to know for how long savings from given system will last.

\footnotetext{
${ }^{22}$ Assume that over a ten year period, the hospital spends $3 \%$ per year on IT. This buys seven new systems over the first five years. Assume that each of these yields $2 \%$ reductions in costs in the out years (5-10). With reasonable discount rates, the cost savings do cover the cost of the IT.
} 
Without further controls, the negative association between IT adoption and future variable costs cannot be interpreted as evidence that hospital information systems are cost reducing technologies. Hospitals that have adopted these systems appear to have lower costs three to five years in the future. Unfortunately, this may be a selection bias - hospitals with falling costs may be the same ones more aggressively adopting IT. The positive relationship between adoption of IT and future costs at the least automated hospitals also argues that some selection bias may exist.

The current study addresses these concerns in several ways. To begin, the fixed effects in the model capture any stable unobserved hospital characteristics that may differentiate hospitals with higher-than-average or lower-than-average operating costs. As a result, any potential selection bias is not based upon the fact that low cost hospitals are rapid adopters while high cost hospitals are not. Further, state-level time trends for costs were also included which implies that the effects seen are not related to cost trend determinants at the state level. Rather, it must be some unobserved time-varying hospital-specific characteristic that leads not only to rising (falling) costs but also to lesser (greater) IT adoption. To rule this out, the specification was relaxed and lead regressions of cost on future adoption of IT were run. Each of these tests provided evidence against the notion of hospital specific time varying characteristics.

The main explanation for the higher costs associated with IT adoption at less automated hospitals rests in the theory of co-invention. As Bresnahan and Greenstein (1996) explain, any organization utilizing IT must undergo an extensive process of co-invention as assets complementary to IT are developed and deployed. This may include new organizational procedures, training of employees, customization of software and other changes, all of which take time to implement. Thus, for lesser automated hospitals, the costs of adoption are higher and benefits are reduced, leading to the patterns in the data. The costs savings, if any exist, are still dwarfed by these additional costs of adopting and implementing the systems.

The presence of high co-invention costs and learning effects also explain the delay in cost declines following adoption at more automated hospitals. In this study, costs continue to decline five years after adoption. One promising direction for future research involves extending this data and attempting to measure if these learning effects extend beyond the five years examined in this 
work.

Beyond the learning issues, the IT data used in this study provide opportunities for a wealth of future research. Matching the application-level data to specific department related costs available on the Medicare Worksheet A files offers the opportunity to obtain more precise and localized estimates of IT cost savings. For example, the current study does not show cost savings from medical records systems. Using data on costs solely within medical records departments may be more accurate and give rise to different results.

More structural approaches are also possible in order to gauge the role of IT in altering the production structure of hospitals. Detailed data on labor, capital, and materials employed by hospitals is readily available, allowing estimation of IT's impact on marginal factor returns and the resulting mix of hospital inputs. Understanding how new IT may alter the capital intensity of hospitals, or the skilled-unskilled labor balance in hospitals, can provide answers to critical policy questions.

Lastly, this same dataset can be matched with health outcomes in order to assess whether IT is a factor in improving hospital quality. Evidence from other industries indicates that IT may not lower costs, but rather increase the quality of output. Assessing whether this is true for hospitals would be valuable information on IT's overall impact on health care.

This study lays the foundation for investigating how IT impacts hospital costs. Future work using this dataset and others will provide greater evidence on the role of IT in shaping the structure, costs, and quality of hospitals. 


\section{References}

Arrow, Kenneth J., "Uncertainty and the Welfare Economics of Medical Care," American Economic Review, December 1963, 53 (5), 941-973.

Bates, David W., Anne C. O’Neil, Deborah Boyle, and Jonathan Teich, "Potential Identifiability of Adverse Events Using Information Systems," Journal of the American Medical Informatics Association, Sept./Oct. 1994, 5 (1), 404-411.

Borzekowski, Ron, "The Adoption and Cost Impact of Hospital Information Systems." PhD dissertation, Stanford University 2002.

Bresnahan, Timothy and Shane Greenstein, "Technical Progress and Co-Invention in Computing and in the Uses of Computers," Brookings Papers in Microeconomic Activity: 1996, 1996, pp. 1-77.

Brynjolfsson, Erik, "The Information Paradox of Information Technology," Communications of the ACM, December 1993, 36 (12), 67-77.

_ _ and Lorin Hitt, "Computing Productivity: Firm-Level Evidence," April 2000. mimeo.

_ and S. Yang, Information Technology and Productivity: A Review of Literature Advances in Computers

Carey, Kathleen, "A Panel Data Design for Estimation of Hospital Cost Functions," The Review of Economics and Statistics, August 1997, 79 (3), 443-453.

Collen, Morris Frank, A History of Medical Informatics in the United States: 1950-1990, American Medical Informatics Association, 1995.

Devaraj, Sarv and Rajiv Kohli, "Information Technology Payoff in the Health-Care Industry: A Longitudinal Study," Journal of Management Information Systems, Spring 2000, 16 (4), $41-67$.

Ellis, Randall P., "Hospital Cost Function Esitmation When Firms May Not Try to Minimize Cost," September 1993.

Grannemann, Thomas W., Randall S. Brown, and Mark V. Pauly, "Estimating Hosptial Costs: A Multiple-Output Analysis," Journal of Health Economics, June 1986, 5, 107-127.

Gruber, Jonathan and Maria Owings, "Physician Financial Incentives and Cesarean Section Delivery," RAND Journal of Economics, Spring 1996, 27 (1), 99-123. 
Harrington, R. W., "First hurdle in ADP: discovering its hospital potentials," Hospitals, January 1964, 38, 39-42.

Harris, Jeffrey E., "The Internal Organization of Hospitals: Some Economic Implications," The Bell Journal of Economics, 1977, 8, 467-482.

Health Care Finance Administration, U.S. Dept. of Health and Human Services, HCFA Hospital Cost Reports - Minimum Dataset Various Years. [Computer File].

Ichniowski, Casey, Kathryn Shaw, and Giovanna Prennushi, "The Effects of Human Resource Management Practices on Productivity: A Study of Steel Finishing Lines," American Economic Review, June 1977, 87 (3), 291-313.

Jydstrup, R. A. and M. J. Gross, "Cost of Information Handling in Hospitals," Health Services Research, 1966, 1, 235-271.

McClellan, Mark and Dan Kessler, "Do Doctors Practice Defensive Medicine?," Quarterly Journal of Economics, May 1996, 111 (2), 353-90.

McGuire, T.G., "Physician Agency," in A.J. Culyer and J.P. Newhouse, eds., A.J. Culyer and J.P. Newhouse, eds., Elsevier Science B.V., 2000, chapter 9.

National Center for Health Statistics, Hyattsville, Maryland: National Center for Health Statistics, 2000.

Pestotnik, Stanley L., David C. Classen, R. Scott Evans, and John P. Burke, "Implementing Antibiotic Practice Guidelines through Computer-Assisted Decision Support: Clinical and Financial Outcomes," Annals of Internal Medicine, May 15 1996, 124 (10), 884-890.

Roberts, Rebecca R., Paul W. Frutos, Ginerva G. Ciavarella, Leon Gussow, Edward K. Menash, Linda M. Kampe, Helen E. Straus, Gnanaraj Joseph, and Robert J. Rydman, "Distribution of Variable vs. Fixed Costs of Hospital Care," JAMA: The Journal of the American Medical Association, February 17 1999, 281 (7), 644-649.

Sheldon I. Dorenfest \& Associates, Ltd., The Dorenfest 3000+ Database 1987, 1990, 1993, 1994. [Computer File].

Tay, Abigail, "Quality Competition in Hospital Care Markets," 2000. mimeo, Columbia University.

Vita, Michael G., "Exploring Hospital Production Relationships with Flexible Functional Forms," Journal of Health Economics, June 1990, 9, 1-21. 
Woolhander, S. and D. U. Himmelstein, "Costs of Care and Administration at For-Profit and Other Hospitals in the United States," New England Journal of Medicine, March 13 1997, 336 (11), 769-774.

Zuboff, Shoshana, In the Age of the Smart Machine: The Future of Work and Power, New York: Basic Books, 1988. 